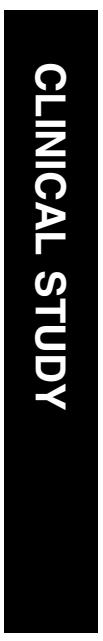

\section{Effects of corneal thickness on the intraocular penetration of travoprost $0.004 \%$}

JM Martinez-de-la-Casa', O Rayward', F Saenz-Frances', E Santos-Bueso', C Mendez-Hernandez', R Herrero-Vanrell², J Garcia-Feijoo' and J Garcia-Sanchez ${ }^{1}$
${ }^{1}$ Servicio de Oftalmologia, Hospital Clinico San Carlos, Departamento de Oftalmologia, Facultad de Medicina, Universidad Complutense de Madrid, Instituto de Investigacion Sanitaria del Hospital Clinico San Carlos (IdISSC) , Madrid, Spain

${ }^{2}$ Facultad de Farmacia, Universidad Complutense, Madrid, Spain

Correspondence: JM Martinez-de-la-Casa, Servicio de Oftalmologia, Hospital Clinico San Carlos, Departamento de Oftalmologia, Facultad de Medicina, Universidad Complutense de Madrid, Instituto de Investigacion Sanitaria del Hospital Clinico San Carlos (IdISSC), Martin Lagos s/n, 28040 Madrid, Spain. Tel: + 34913303977 ; Fax: + 34913303975 . E-mail: martinezcasa@ ya.com

Received: 31 October 2011 Accepted in revised form: 19 March 2012 Published online: 4 May 2012

\begin{abstract}
Purpose To determine whether the intraocular penetration of travoprost $0.004 \%$ is affected by central corneal thickness. Methods Sixty-four patients who were scheduled for cataract surgery without any other ophthalmologic pathology of significance were enroled in this study. At $120 \mathrm{~min}$ before surgery, one drop of travoprost $0.004 \%$ was instilled in the eye to be operated on. At the start of surgery, a sample of aqueous humour was extracted to subsequently determine its AL-5848 concentration. These concentrations were compared among three groups of patients established according to central corneal thickness measurements obtained by ultrasound pachymetry.
\end{abstract}

Results Mean AL-5848 concentrations were $3.27 \pm 2.03 \mathrm{ng} / \mathrm{ml}$ in Group I (CCT $<511$ microns), $3.27 \pm 2.44 \mathrm{ng} / \mathrm{ml}$ in Group II (CCT $\geq 511$ and $\leq 574$ microns), and $2.73 \pm 2.15 \mathrm{ng} / \mathrm{ml}$ in Group III (CCT $>574$ microns), indicating no significant differences among the groups.

Conclusions We were unable to demonstrate the greater or lesser penetration of travoprost depending on corneal thickness, which could explain differences in patient responses to this drug.

Eye (2012) 26, 972-975; doi:10.1038/eye.2012.74; published online 4 May 2012

Keywords: glaucoma; corneal thickness; intraocular pressure; prostaglandin; intraocular penetration

\section{Introduction}

Elevated intraocular pressure (IOP) is the main risk factor identified to date for the appearance and progression of glaucoma. ${ }^{1-3}$ So far, the only therapeutic strategy that has proved effective at delaying progression of glaucoma has been the reduction of IOP using drugs, laser, or surgical treatment. ${ }^{4-6}$

Prostaglandin analogues are the current first-line agents for the medical treatment of glaucoma owing to their IOP-reducing capacity $^{7-9}$ and their systemic safety profile. Ocular hypertension studies have shown the possible effects of corneal thickness on IOP measurements. In a postanalysis of the data provided by the Ocular Hypertension Treatment Study, ${ }^{7,10}$ Brandt et al ${ }^{11}$ examined the pressure-lowering effects of the different hypotensive antiglaucoma medications available according to central corneal thickness. This study concluded that there was significant correlation between central corneal thickness and the reduction obtained in IOP such that patients with a thicker cornea show a reduced response to commonly used pressure-lowering agents. This effect was more significant in patients treated with prostaglandin analogues than those treated with beta-blockers. To explain this finding, the authors suggested that, although unlikely, differences in central corneal thickness might affect the pharmacokinetics of topical drug penetration into the eye. To the best of our knowledge, no prior study has set out to test this hypothesis in vivo. The present study was designed to determine whether differences exist in the absorption of travoprost $0.004 \%$ (Travatan, Alcon Cusí, Barcelona, Spain) according to central corneal thickness.

\section{Materials and methods}

Sixty-four patients scheduled to undergo cataract surgery at our institution who fulfilled 
Table 1 Inclusion and exclusion criteria

\begin{tabular}{l} 
Inclusion criteria \\
Age above 18 years \\
Patients with surgical-stage cataract \\
No significant eye or general pathology other than cataract \\
that could be related to modified corneal properties \\
No prior surgery that may have modified the properties of the \\
cornea \\
No topical hypotensive treatment received before the start of \\
the study \\
Capacity to understand the study procedures and provide \\
written informed consent \\
Exclusion criteria \\
Dry eye or any corneal pathology \\
Best-corrected visual acuity less than counting fingers in either \\
eye \\
Significant ocular pathology other than senile cataract \\
Prior eye surgery \\
Active infection \\
Systemic corticosteroid treatment \\
Poorly controlled systemic pathology \\
Mental disability or any other limitation for providing \\
informed consent \\
Inability to attend the programmed visits during the study \\
Known sensitivity to any of the medications used in the study \\
Participation in any other investigation in the 6 months before \\
the study outset \\
Chronic topical ocular treatment including the use of artificial \\
tears with preservatives \\
\hline
\end{tabular}

the inclusion criteria (Table 1) were recruited for this study. The eyes selected had no ophthalmologic condition other than cataract or a prior history of ocular surgery or trauma. According to the tenets of the Declaration of Helsinki (World Medical Association Declaration of Helsinki: Ethical Principles for Medical Research Involving Human Subjects: Adopted by the 18th WMA General Assembly, Finland, June 1964, and amended by the 59th WMA General Assembly), informed consent was obtained from each patient, and the study protocol was approved by the institution's review board.

Between 7 and 30 days before surgery, each patient was subjected to a complete ophthalmologic examination, and their clinical records were examined to rule out any other ocular or systemic diseases, specifically any condition that could affect the absorption of the drug (Table 1 provide the inclusion and exclusion criteria). Central corneal thickness was determined by ultrasound pachymetry (OcuScan RxP Measuring System, Alcon Laboratories, Inc., Fort Worth, TX, USA).

Two hours before surgery, one drop of travoprost $0.004 \%$ was administered to the eye to be operated on Once the drug had been instilled, the eye was kept closed for $5 \mathrm{~min}$ with lacrimal punctal occlusion. For each patient, a new vial of eye drops was used, and the drop was instilled after discarding the first 10 drops.
No other topical eye medication was applied before surgery, with the exception of a drop of tetracaine hydrochloride and oxybuprocaine hydrochloride (Colircusi Anestésico Doble, Alcon Cusí, Barcelona, Spain) instilled immediately before performing a paracentesis with a $23 \mathrm{G}$ needle to obtain a sample of aqueous humour. A deviation of $\pm 5 \mathrm{~min}$ from the pre-established $120 \mathrm{~min}$ between instilling the drop and obtaining the sample was allowed. Once the humour sample had been obtained, the pupil was dilated through the intracameral administration of $0.4 \mathrm{ml}$ of lidocaine $1 \%$ with adrenalin 1/10000, for subsequent standard phacoemulsification with the implant of an intraocular lens in the capsular bag. All paracenteses and surgeries were performed by the same investigator.

Once the aqueous humour sample had been extracted, it was transferred to a polypropylene vessel suitable for freeze storage. The samples were kept frozen at $-70{ }^{\circ} \mathrm{C}$ until they were sent on dry ice to Simbec Research Limited, Merthyr Tydfil, Wales, for their analysis. The concentration of AL-5848, the active hydrolysis product of the synthetic prostaglandin analogue travoprost, was determined by a validated high-performance liquid chromatography-tandem mass spectroscopy (LC-MS-MS) method ${ }^{12}$ (determination of AL-5848 in NZW Rabbit Aqueous Humour by Liquid Chromatography-Tandem Mass Spectrometry after Dosing with Several Formulations containing Travoprost. AlconCusi Protocol Number: EM-N-04-018). The investigator who analysed the aqueous humour samples was blind to the clinical data of the patients.

Patients were selected according to central corneal thickness to create 3 groups of 20 subjects each: 510 microns or less (Group I), between 511 and 574 microns, both inclusive (Group II), and 575 microns or more (Group III). This division was based on a study conducted in a population of similar characteristics, ${ }^{13}$ in which Group II corresponded to the mean corneal thickness \pm 1 SD. Other authors have reported a similar distribution of central corneal thicknesses in normal subjects. ${ }^{14}$

All statistical tests were performed using the SPSS 18.0 software (SPSS Inc., Chicago, IL, USA). The Kolmogorov-Smirnov test was used to check the normal distribution of quantitative data. Data were compared using the Student's $t$-test and Pearson's linear correlation test. The level of significance was set at $P<0.05$.

Statement of Ethics: We certify that all applicable institutional and governmental regulations concerning the ethical use of human volunteers were followed during this research. 


\section{Results}

Sixty-four aqueous humour samples were obtained from 64 patients. Of these 64 samples, 4 were of insufficient volume for analysis. Hence, our statistical analysis was conducted on the data available for the 60 remaining samples (20 Group I, 20 Group II, and 20 Group III samples).

Ten samples had a concentration that was too low for quantification (2 in Group I, 4 in Group II, and 4 in Group III). Excluding these samples, mean AL-5848 concentrations detected in the aqueous humour were as follows: $3.27 \pm 2.03 \mathrm{ng} / \mathrm{ml}$ in Group I (CCT $<511$ microns), $3.27 \pm 2.44 \mathrm{ng} / \mathrm{ml}$ in Group II (CCT $\geq 511$ and $\leq 574$ microns), and $2.73 \pm 2.15 \mathrm{ng} / \mathrm{ml}$ in Group III (CCT $>574$ microns). No significant differences emerged when these concentrations were compared among the groups.

In addition, when we considered the complete data set, no significant correlation was detected between AL-5848 concentration and central corneal thickness $(r=-0.72$, $P=0.583)$.

No patient suffered any intraoperative or postoperative complications.

\section{Discussion}

Recent studies have shown that following the instillation of ocular hypotensive drugs, patients with a thicker cornea undergo a lower drop in intraocular pressure than patients whose cornea is thinner. ${ }^{11,15,16}$ Brandt et al ${ }^{11}$ reported a significant negative correlation between central corneal thickness and the hypotensive effect produced after 4-6 weeks of treatment with non-selective beta-blockers and prostaglandin analogues in patients with ocular hypertension. These authors put forward three hypotheses to try to explain these findings. One of these was that the real pressure of patients with a thicker cornea is lower than the reading obtained by Goldmann tonometry, such that starting with a lower pressure both the final pressure and percentage reduction in pressure would be lower. The second hypothesis was that a thicker cornea is likely to be more rigid and the effect of this corneal stiffness on intraocular pressure measurements could be greater for lower pressures, such that the capacity to record a reduction in intraocular pressure in response to the use of a drug would be diminished in patients with thick corneas. Finally, the third hypothesis proposed by Brandt et al was the possible different pharmacokinetics of a drug depending on corneal thickness, determining that the intraocular concentration of the drug would be lower in patients with a thicker cornea and consequently its pressurereducing effect would also be lower. The authors acknowledged that there are no data to back this theory, as no study until now had tried to correlate intraocular drug concentrations with central corneal thickness in humans or experimental animals.

Other authors have noted the lesser efficiency of prostaglandin analogues in eyes with thick corneas. In a multicenter study, Harasymowycz et al ${ }^{15}$ examined the effect of central corneal thickness on the pressurelowering efficacy of a 6-week course of travoprost $0.004 \%$ in 379 patients with open-angle glaucoma or ocular hypertension. Among the patients with glaucoma, the hypotensive response was significantly lower in those with thick corneas. Johnson et al ${ }^{16}$ obtained similar results in a study conducted in ocular hypertensive patients and healthy volunteers.

The present study was designed to assess one of the theories initially proposed by Brandt et al ${ }^{11}$ to explain the lower hypotensive efficiency of prostaglandin analogues in patients with thick corneas. In view of our results, however, it could not be concluded that significant differences exist in the intraocular penetration of travoprost as a function of corneal thickness.

One of the limitations of our study was that AL-5848 determination was performed after a single dose of the drug, which does not reflect the true situation of antiglaucoma treatments that are continued for long time periods. Chronic exposure to these drugs, often containing preservatives, could modify the permeability of the corneal epithelium ${ }^{17,18}$ and affect the concentration of the main active ingredient in the anterior chamber. We are thus unaware if this altered permeability might similarly affect corneas of different thicknesses. On the other hand, prolonged exposure to prostaglandin analogues seems to induce structural changes at the level of the corneal stroma, and numerous studies have revealed that chronic treatment with prostaglandins reduces central corneal thickness. ${ }^{15,19-21}$ This could also affect the results obtained when translated to the real situation of the treatment of patients with glaucoma.

Another limitation of our study was the small sample size. The technical difficulties involved and costs of studies of this type make it difficult to work with large patient numbers. Therefore, the study was possibly underpowered to detect a statistically significant and clinically significant difference between the groups. Thus, we cannot completely rule out the possible influence of corneal thickness on the intraocular penetration of topical drugs. The lack of data on the link between drug intraocular concentration and clinical response in humans makes it impossible to establish a priori which is the intraocular concentration difference that will determine a clinically meaningful change in intraocular pressure. Outside these limitations and according to the results of this study, it would seem that 
corneal thickness has no marked effect on the intraocular concentration of topically administered drugs. Other factors such as tear clearance could have an important role in the intraocular penetration of drugs, and this could explain the presence, in our three groups of patients, of samples with non-detectable drug concentrations. Further research is needed to identify possible factors explaining the high variability in intraocular drug concentration observed in each of the patient groups.

\section{Summary}

\section{What was known before}

- There is a significant correlation between central corneal thickness and the reduction obtained in IOP. This effect is more significant in patients treated with prostaglandin analogues than those treated with beta-blockers. Differences in central corneal thickness might affect the pharmacokinetics of topical drug penetration into the eye. To the best of our knowledge, no prior study has set out to test this hypothesis in vivo.

\section{What this study adds}

- It would seem that corneal thickness has no marked effect on the intraocular concentration of topically administered drugs.

\section{Conflict of interest}

The authors declare no conflict of interest.

\section{Acknowledgements}

The sources of funding were from (a) Instituto de Salud Carlos III, 'Red temática de Investigación Cooperativa. Proyecto RD07/0062: Patología ocular del envejecimiento, calidad visual y calidad de vida', (b) Grupo de Investigación de la Universidad Complutense de Madrid 920415-GR58/08. Unrestricted grant was received from Alcon Laboratories for the processing of study samples.

\section{References}

1 Mitchell P, Smith W, Attebo K, Healey PR. Prevalence of open-angle glaucoma in Australia. The Blue Mountains Eye Study. Ophthalmology 1996; 103: 1661-1669.

2 Sommer A, Tielsch JM, Katz J, Quigley HA, Gottsch JD, Javitt J et al. Relationship between intraocular pressure and primary open angle glaucoma among white and black Americans. The Baltimore Eye Survey. Arch Ophthalmol 1991; 109: 1090-1095.

3 Weih LM, Nanjan M, McCarty CA, Taylor HR. Prevalence and predictors of open-angle glaucoma: results from the visual impairment project. Ophthalmology 2001; 108: 1966-1972.

4 Leske MC. The epidemiology of open-angle glaucoma: a review. Am J Epidemiol 1983; 118: 166-191.

5 Leske MC, Heijl A, Hussein M, Bengtsson B, Hyman L, Komaroff E. Factors for glaucoma progression and the effect of treatment: the early manifest glaucoma trial. Arch Ophthalmol 2003; 121: 48-56.

6 Heijl A, Leske MC, Bengtsson B, Hyman L, Hussein M. Reduction of intraocular pressure and glaucoma progression: results from the Early Manifest Glaucoma Trial. Arch Ophthalmol 2002; 120: 1268-1279.

7 Kass MA, Heuer DK, Higginbotham EJ, Johnson CA, Keltner JL, Miller JP et al. The Ocular Hypertension Treatment Study: a randomized trial determines that topical ocular hypotensive medication delays or prevents the onset of primary open-angle glaucoma. Arch Ophthalmol 2002; 120: 701-713; discussion 829-30.

8 Liu CJ, Chou JC, Hsu WM, Liu JH. Effects of latanoprost 50 micrograms $/ \mathrm{ml}$ on Chinese patients with primary open-angle glaucoma and ocular hypertension. Zhonghua $Y_{i}$ Xue Za Zhi (Taipei) 1999; 62: 703-709.

9 Vass C, Hirn C, Sycha T, Findl O, Bauer P, Schmetterer L. Medical interventions for primary open angle glaucoma and ocular hypertension. Cochrane Database Syst Rev 2007, CD003167.

10 Gordon MO, Beiser JA, Brandt JD, Heuer DK, Higginbotham EJ, Johnson CA et al. The Ocular Hypertension Treatment Study: baseline factors that predict the onset of primary open-angle glaucoma 2002; Arch Ophthalmol 120: 714-720; discussion 829-830.

11 Brandt JD, Beiser JA, Gordon MO, Kass MA. Central corneal thickness and measured IOP response to topical ocular hypotensive medication in the Ocular Hypertension Treatment Study. Am J Ophthalmol 2004; 138: 717-722.

12 Zammataro A, Civiale C, Saletti R, Foti S. Development and validation of a liquid chromatography/electrospray ionization tandem mass spectrometry method for the quantification of latanoprost free acid in rabbit aqueous humor and ciliary body. J Mass Spectrom 2011; 46: 1168-1174.

13 Sanchez-Tocino H, Bringas-Calvo R, Iglesias-Cortinas D. [Correlation between intraocular pressure, paquimetry and keratometry in a normal population]. Arch Soc Esp Oftalmol 2007; 82: 267-272.

14 Doughty MJ, Zaman ML. Human corneal thickness and its impact on intraocular pressure measures: a review and meta-analysis approach. Surv Ophthalmol 2000; 44: 367-408.

15 Harasymowycz PJ, Papamatheakis DG, Ennis M, Brady M, Gordon KD. Relationship between travoprost and central corneal thickness in ocular hypertension and open-angle glaucoma. Cornea 2007; 26: 34-41.

16 Johnson TV, Toris CB, Fan S, Camras CB. Effects of central corneal thickness on the efficacy of topical ocular hypotensive medications. J Glaucoma 2008; 17: 89-99.

17 Horsley MB, Kahook MY. Effects of prostaglandin analog therapy on the ocular surface of glaucoma patients. Clin Ophthalmol 2009; 3: 291-295.

18 Kahook MY, Noecker RJ. Comparison of corneal and conjunctival changes after dosing of travoprost preserved with sofZia, latanoprost with $0.02 \%$ benzalkonium chloride, and preservative-free artificial tears. Cornea 2008; 27: 339-343.

19 Schlote T, Tzamalis A, Kynigopoulos M. Central corneal thickness during treatment with travoprost $0.004 \%$ in glaucoma patients. J Ocul Pharmacol Ther 2009; 25: 459-462.

20 Stefan C, Dumitrica DM, Tebeanu E, Nae I, Sapundgieva A, Dragomir L. [Prostaglandin analogues and central corneal thickness]. Oftalmologia 2007; 51: 95-99.

21 Hatanaka M, Vessani RM, Elias IR, Morita C, Susanna R Jr. The effect of prostaglandin analogs and prostamide on central corneal thickness. J Ocul Pharmacol Ther 2009; 25: 51-53. 